\title{
Creative approaches to mental health: a critical analysis of the mindfulness agenda in Sussex
}

\author{
Kate Spiegelhalter
}

\begin{abstract}
Mindfulness is a packaged intervention with current popularity in East Sussex, and this study explores how it is embedded in mental health services, the processes of the gathering and presentation of evidence, how the experience of patients is organizationally shaped and the importance of indirect interventions. These forms of interventions are what has been termed 'choice architecture' by proponents of the 'nudge agenda', describing the way that decisions and behaviour are influenced by how the choices are presented or designed ${ }^{1}$. I want to explore the feasibility of applying indirect interventions to mindfulness in order to increase take-up rates, evaluative mechanisms and follow-up support, based on the patient perspective. Mindfulness-based cognitive therapy (MBCT) was recommended by NICE in their guidelines in 2004, was brought fully into the mainstream and has now been specifically adapted for psychosis. My research is on the interaction between mindfulness as an innovative therapy, a marginalised group of people who experience psychosis, and the currently popular behavioural economics (nudge) agenda. The nudge agenda is being promoted on the basis of cost-effectiveness, the aptness of its ideology to the current political climate, and its evidence base in particular case studies. The use of creative indirect interventions such as nudge, 'when carefully crafted and applied', can be 'a positive means of communication between physician and patient, ${ }^{2}$.
\end{abstract}

Key Words: Mindfulness-Based Cognitive Therapy (MBCT), mindfulness, behavioural economics, nudge, happiness, well-being, psychosis, chronic pain, self, body

$* * * * *$

\section{Background}

The costs of mental health problems in England have been estimated at $£ 105$ billion, with treatment costs expected to double over the 20 years to come $\mathrm{e}^{3}$. David Cameron has claimed that the Coalition Government's success will be measured by the nation's well-being, not just by the state of the economy. There has also been an increase in cost-based arguments in favour of investment in changing certain cost-inflicting behaviours within the population. 
My research will focus on mindfulness as an innovative therapy, people who experience psychosis, and the possibilities of creative approaches in mental health and well-being. This is an ethnographic study of an intervention using a case study approach, and uses a qualitative methodology in contrast to the dominant paradigm of the RCT. A critical perspective on the efficacy and evidence base of both the mindfulness and nudge agendas will be maintained throughout.

\section{Objectives}

Can mindfulness be used as a specific technique and made the focus of behavioural interventions in order to increase levels of well-being for people experiencing psychosis?

Sub objectives:

1. What is mindfulness and who is promoting and working with it in the field of mental health?

2. How is mindfulness being used and engaged with in the field of psychosis, and specifically through on-going research in the area?

3 . How is innovation being evaluated and what influences involvement, acceptability and usability after a formal intervention?

4. Could the mindfulness paradigm be built on with indirect interventions and subtle changes to organisation and delivery to increase its value for users and practitioners?

5. What are the lessons for future mental health policy and practice, both within Sussex and nationally?

\section{Mindfulness}

Mindfulness involves 'intentionally bringing one's attention to the internal and external experiences occurring in the present moment' and is "often taught through a variety of meditation exercises" ${ }^{4}$. It is a way of experiencing things 'as they are', and paying attention in a non-judgmental way to how things are around us. Mindfulness sessions and therapies, with their emphasis on the present moment, 
on the breath and on the body may seem to stand in contrast to behavioural economics with its focus on libertarian individual choice. However the holistic orientation of mindfulness puts the responsibility for health and illness in the hands of the individual, and thus can be seen as fitting with Western valuing of the ability to take decisions, make informed choices and take responsibility, where competence in these regards is seen as vital to forging one's own identity.

Psychological interventions that use mindfulness meditation are being used to benefit people affected by long term mental and physical health problems. Mindfulness has been used successfully in public health provision for 32 years since it originated in the USA in $1979^{5}$. Mindfulness-Based Cognitive Therapy (MBCT) was then developed collaboratively between Mark Williams, John Teasdale and Zindel Segal in Bangor and Cambridge, UK and Toronto, Canada. MBCT was recommended by NICE in their guidelines as the treatment of choice for the prevention of future depression for people who have experienced 3 or more episodes in 2004 and was brought into the mainstream of public health ${ }^{6}$.

Mindfulness interventions have not until now been made available to people with a diagnosis of schizophrenia, despite levels of need. The experience of hearing voices is common amongst people who have a diagnosis of schizophrenia and is often associated with high levels of distress, low self-esteem and social isolation ${ }^{7}$. Professor Paul Chadwick's research team has adapted mindfulness meditation for people who hear distressing voices and have developed a mindfulness-based group therapy. This therapy has been piloted and was found to be beneficial as voice hearers reported lessening distress, improved personal control and improved psychological health ${ }^{8}$. In this project a critical perspective will be maintained of the degree to which service user and participant views and experiences have been incorporated into clinical trials and practices. 


\section{Indirect Interventions}

The area of behavioural economics is an interesting one, not because it is particularly recent, but rather because of the potential and need for an expansion of the evidence base for the application of choice architecture in mental health.

Behavioural psychology and neuroscience have collectively worked to expose the different ways in which it is possible to shape human behaviour through the subtle targeting of the human conscious and subconscious by various 'nudge' strategies ${ }^{9}$. Behavioural economics has borrowed from psychology, neuroscience, and economics, and choice architecture is one of a range of indirect interventions in this field. Interventions led by the Behavioural Insights Team (BIT), that aims to 'identify promising interventions that modify physical, social, economic and legislative environments to improve health related behaviours ${ }^{10}$, range from fairly traditional advertising campaigns, sophisticated design initiatives that focus on spatial arrangements (e.g. the layout of school canteens), to administrative techniques that attempt to ensure certain forms of optimal behaviour ${ }^{11}$.

Rather than top-down state intervention, recent government initiatives use the softer powers of social marketing tools to build public awareness and change behaviour' through the establishment of new behavioural norms ${ }^{12}$. A fundamental challenge for health behaviour theory is moving from theory to action, which involves pull-through from research to practice ${ }^{13}$. Human behaviour is influenced by psychological, non-rational, unconscious motivations ${ }^{14}$, and the nudge agenda can 'provide a partial solution to the quandary of why people don't care for their health the way they might rationally be expected to ${ }^{15}$, as well as a less obtrusive and more costeffective than more top-down interventions, taking its starting point from the current state and stage of mindfulness services (see ideas outlined in Appendix 2). 


\section{Collaboration}

Collaborative links have been established with members of the government's Behavioural Insight Team (BIT), SPFT and other services across the public and private sectors providing mindfulness services such as MIND. SPFT has identified innovative therapies in mental health, such as mindfulness, as key interests and priorities, and recently started a study; Mindfulness-based therapy groups for distressing voices $(M 4 V)$ : A pragmatic randomised controlled trial $(R C T)$. This study is funded by the National Institute for Health Research (NIHR) (£183,000) and aims to evaluate the effectiveness of a new kind of 'mindfulness-based group therapy' which seeks to help people learn new ways of managing and living with distressing voices. Through this collaboration I will examine processes within M4V and the engagement with M4V by physicians and patients, including factors affecting clinical decision making.

\section{SPFT; 'Market leader'}

SPFT is a self-proclaimed 'market leader' in this area and the Research \& Development Department recently secured two nationally significant research grants from the National Institute for Health Research (NIHR) worth almost $£ 400,000$. This is a new area of research however, and more evidence is needed of how similar forms of group therapy can bring about improvements in general wellbeing, voice omnipotence, self-esteem and feelings of hopelessness. Dannahy et al argue that these are more worthwhile aims and primary outcomes than symptom reduction ${ }^{16}$.

Saving money through preventative measures fits the aims of the current government ${ }^{17}$, and evidence has suggested mindfulness to be effective in this way. The cost argument for the provision of mindfulness courses on the NHS is thus a pertinent one. The question of who should bear the cost of provision according to need also needs to take into account the current postcode lottery of healthcare 
provision across the UK. This is a time of change for SFPT and the NHS as a whole, with the changes in the commissioning process currently occurring ${ }^{18}$. This makes current decisions about funding and resource allocation difficult. Mindfulness is an industry whose opportunities for commercial development might be increased under the new law.

\section{Chronicity, 'the problem of psychosis': diagnosis and treatment}

The focus on emotional health above can be contrasted with serious mental illness (SMI) and chronic illness (CI) with psychosis falling under this category. The term psychosis is used to describe a 'mental health problem that can affect the brain, so that there is a loss of contact with reality ${ }^{19}$. About 3 out of every 100 people will experience a psychotic episode, making psychosis more common than diabetes. The illness is 'irrevocably associated with 'dangerousness' as defined by the Mental Health Act $(1953,1983)$ as the propensity to harm self or others ${ }^{20}$. It can be treated however, and many people make a full recovery ${ }^{21}$.

There are significant gaps in the literature exploring mindfulness and psychosis, and the need for myths around this client group to be engaged with and deconstructed. Between $4 \%$ and $5 \%$ of people experience some form of hallucination each year, most commonly hearing voices ${ }^{22}$. Psychiatric labels can 'tend to be stigmatizing because they implicate the negotiation of the self ${ }^{23}$. The blurring of the distinction between 'normal' and 'pathological' behaviours from the growing popularity of psychoanalytical ideas however helped to destigmatize mental illness generally ${ }^{24}$. I am working collaboratively with service user researchers to explore the nature of these therapeutic relationships.

The applicability of mindfulness for people experiencing psychosis has also been questioned in the literature ${ }^{25}$, and whether it is 
appropriate to want to be inside one's body and thoughts when hearing voices. The varied experiences of psychosis is still seen as a reclusive experience, and doubts have been raised about whether this is a productive thing to $\mathrm{do}^{26}$. I want to explore the embodied experiences and user narratives behind the M4V trial.

'Third wave' acceptance-based theory and practice has focused mainly on how people relate with and respond to voices and other psychotic experiences ${ }^{27}$. Recent studies have been exploring these arguments and expand the evidence base around this debate. Along with Chadwick, Mark Hayward, Lana Jackson and Anne Cooke have done recent work on developing a positive relationship and engagement with the voices by consciously trying to find a way of living peacefully with rather than attempt to defeat them ${ }^{28}$. This therapy tries to challenge the negative idea of the self as bad, inadequate or flawed, and broaden this sense of self so that the voices become one part of this self rather than the whole ${ }^{29}$.

\section{Body and mind}

More integrated and holistic models of health and illness - of which MBCT is part - are now 'permeating many areas of medical education and health care practice ${ }^{30}$. The growth of public interest in CAM and emphasis on emotional health rather than mental illness has led to new conceptions of the body and mind relationship ${ }^{31}$. A key assumption of biomedicine is that the body and the mind can be treated separately, and moving beyond the mind/body split 'entails a re-examining of the medicalisation of emotional distress/disorderwith subsequent consequences for diagnosis and treatment ${ }^{32}$. Due partly to the influence of Foucault's discourse analysis, it is now acknowledged that disease (or a lack of well-being or depression/anxiety) is 'located not merely in the anatomy but in the body of a 'person', which invariably resides within a wider social context ${ }^{33}$. 
Associated with what Nettleton terms 'an increasingly healthist society' is the 'commercialization, commodification and consumption of health and health lifestyles ${ }^{34}$. The nudge agenda is part of this move towards choosing healthy lifestyles and behaviours, and 'rethinking across the traditional divisions between mental and physical conditions ${ }^{35}$. This focus on choice is a critical link between this agenda and that of health promotion, often neglecting a focus as to what affects the degree of choice an individual has. The application of a paternalistic state policy through indirect interventions could paradoxically lead to more people developing an independent relationship with their bodies separate from the state as a product of a mindfulness course.

\section{Methodology}

The methodology adopted for this study is outlined Appendix 1. SPFT's RCT aims to recruit approximately 144 (currently projected to recruit 105) service users who hear voices, of whom I hope to interview 10-15. This qualitative research will be carried out in collaboration with service user advisory panels, and peer researchers who will carry out the same number of interviews, using a collaborative topic guide.

\section{Ethical issues and critiques}

In terms of the ethics of applying indirect interventions to mental health, I will be careful not to confuse causation with correlation, and will infer rather than assume what the results indirect interventions may be $\mathrm{e}^{36}$. Participants of this study will therefore not be treated as blind subjects waiting to be nudged, nor will it be assumed that one individual's response to an intervention will apply to all in that sample population. This will involve the incorporation of valuesbased practice in which 'the values of individual patients are central to evidence-based clinical decision-making ${ }^{37}$. This is particularly relevant when interviewing participants who are experiencing 
psychosis.

Despite the popularity of mindfulness and number of academic papers written on this subject, the empirical literature on the effects of mindfulness training contains many methodological weaknesses ${ }^{38}$. Control groups in some studies have not been given an intervention or compared to other specific psychological approaches ${ }^{39}$. Although most of studies show 'statistically significant improvements in a wide range of dependent variables, none controlled for passage of time, demand characteristics, or placebo effects, or compared MBSR to other treatments ${ }^{40}$. If mindfulness is being compared to nothing as a measurement of success and effectiveness, it is not surprising that it is then found to be effective.

These methodological weaknesses make it difficult to draw strong conclusions about effects, and individual participant experience. The M4V study is thus aiming to use a strong research design to establish if Mindfulness Based Therapy (MBT) groups really add to the benefits derived from the usual care received from mental health teams ${ }^{41}$.

Indirect interventions require informed consent at some stage, 'lest the nudge therapy become ethically questionable and clinically ineffective ${ }^{42}$. The fact that nudge 'works better in the dark' though means that choices and decisions made are not fully autonomous ${ }^{43}$ and raises questions about whether these actions can then be said to be 'irrational ${ }^{44}$. Critics of nudge and libertarian paternalism argue that 'attempts to change people's lifestyle choice are potentially patronising and condescending' and embody 'excessive state interference'. The use of public authority to change citizens' behaviours, even if the altered behaviours are better for the citizens themselves, violates spheres of privacy, integrity, integrity and autonomy, is subject to extensive debate ${ }^{45}$. These ethical and moral critiques will be taken into serious consideration when considering 
applying choice architecture to the field of mental health and mindfulness courses, particularly for people experiencing psychosis.

\section{Expected conclusions}

More evidence can be generated of how far similar forms of group therapy can bring about improvements in general well-being, voice omnipotence, self-esteem and feelings of hopelessness. The use of multiple, integrated approaches, is particularly useful in the evaluation of the effects of complex health care interventions, and this research is taking an original application of established psychological and behavioural techniques to mindfulness therapies and techniques.

The NHS (in its current fragile state ${ }^{46}$ ) is increasingly self-identifying as a research-driven organisation ${ }^{47}$. This study engages with its current research concerns, and will explore the relationship between the evidence base for mindfulness and what is happening in practice, exploring the attitudes of the local authority, charities and other organisations, and policy makers within government to mindfulness as a therapeutic option. This is a study of the institution of SPFT and how it deals with innovation, adding value to this field by bringing together theories from behavioural economics (choice architecture) with sociological concerns regarding the organisation of mental health services, their delivery and their effects on users. Qualitative research such as this can 'support the design of interventions and improve understanding of the mechanisms and effects of complex healthcare interventions ${ }^{48}$. From this study I then hope to be in a position to make recommendations for new or better-targeted interventions in this field.

\section{Notes}

${ }^{1}$ The Inter-Disciplinary Press uses the Chicago Manual of Style $\left(16^{\text {th }}\right.$ Edition) for all referencing conventions, using the notes and bibliography system in particular. 


\section{Bibliography}

Appleby, John, Ham, Chris, Imison, Candice \& Jennings, Mark. Improving NHS productivity, More with the same not more of the same (Kings Fund Report, 2010) Viewed

18.6.12<www.kingsfund.org.uk/document.rm?id=8723Similar>

Ariely, Dan. Predictably Irrational-The Hidden Forces that Shape Our Decisions

(London: Harper Collins, 2008)

Baer, Ruth. Mindfulness training as a clinical intervention: A conceptual and empirical review (Clinical Psychology: Science and Practice, 10(2), 2003), 125

Berry, C., Gerry, L., Hayward, Mark, Chandler, Ruth. Expectations and illusions: a position paper on the relationship between mental health practitioners and social exclusion. Journal of Psychiatric and Mental Health Nursing. 17, 411-421, 2010

Bovens, Luke The Ethics of Nudge. In Grüne-Yanoff, Till and Hansson, Sven Ove, (eds.) Preference change: approaches from philosophy, economics and psychology. Springer, pp. 207-219, 2009

Cabinet Office Institute for Government (2010), Viewed 18.6.12 $<$ http://www.instituteforgovernment.org.uk/content/133/mindspaceinfluencing-behaviour-through-public-policy>

Centre for Mindfulness Research and Practice, Bangor University: viewed 26.6.12<http://www.bangor.ac.uk/mindfulness/> 
Davies, Mark. The NHS reform debate must include patients. Wednesday 4 May 2011 Viewed

27.3.12<http://www.guardian.co.uk/society/joepublic/2011/may/04/n hs-reform-debate-include-patients-charities>

Department of Health, No health without mental health A crossgovernment mental health outcomes strategy for people of all ages (2011)<http://www.dh.gov.uk/prod_consum_dh/groups/dh_digitalass ets/documents/digitalasset/dh_124058.pdf>, 2

Fulford, Bill. Values-Based Practice: A New Partner to EvidenceBased Practice and A First for Psychiatry? Mens Sana Monographs, Vol: 6, Issue: 1, 10-21, 2008

Gold, Alan, and Lichtenberg, Don't call me "nudge": the ethical obligation to use effective interventions to promote public health. (The American journal of bioethics: AJOB,12 (2), 2012),18

Hayes, S.C. (2004). Acceptance and Commitment Therapy, Relational Frame Theory, and the Third Wave of Behavior Therapy. Behavior Therapy, 35, 639-665, 2004

Jackson et al in Isabel Clarke Psychosis and Spirituality - Exploring the New Frontier (London: Wiley-Blackwell, 2010)

Jones, R., Pykett, J. and Whitehead, M. 'Governing temptation: Changing behaviour in an age of libertarian paternalism'. Progress in Human Geography 35: 483, 2011

Lewin, S., Glenton, C., Oxman, A. Use of qualitative methods alongside randomised controlled trials of complex healthcare interventions: methodological study. BMJ; 339:b3496, 2009 
Manning, W. Keeler, E. Newhouse, J. Sloss, E. Wasserman, J. The costs of poor eating habits - A RAND study. London: Harvard University Press, 1991

NHS Clinical trials and Medical research (http://www.nhs.uk/conditions/clinicaltrials/pages/introduction.aspx): viewed 16.6.12

Nettleton, Sarah. The Sociology of Health and Illness (Cambridge: Polity Press, 2010), 21

Pilgrim, D. \& Rogers, A. A Sociology of Mental Health and Illness (4th Ed). Berkshire: Open University Press, 2010

Public Services Commission (2010), 5 $<\mathrm{http}: / / \mathrm{www} .2020$ publicservicestrust.org/page.asp?p=3131>

Rainford, P. and Tinkler, J. in Design Council Seminar Series 23rd February 2011. 'Innovating Through Public Services Seminar Series 2010-2011', Seminar 4: Designing for Nudge Effects: How behaviour management can ease public sector problems', 2010

Rethink, Viewed 18.6.12<http://www.rethink.org>

Shumaker, S, Ockene, J, \& Riekert, K (ed). The Handbook of Behaviour Change, 3rd Edition. New York: Springer Publishing Company, 2009

Tien, AY Distributions of hallucinations in the population. Social Psychiatry and Psychiatric Epidemiology, 26, 287-292, 1991

Thaler, Richard \& Sunstein, Cass. Nudge- Improving Decisions about health, wealth and happines (London: Penguin Books Ltd, 2009), 5 
Kate Spiegelhalter is a PhD student at the University of Sussex, and holds a studentship from the Economic and Social Research Council. She is interested in the importance of effective (and creative) preventative mental health service provision, health inequalities, and the potential that mindfulness has to increase levels of well-being and resilience.

\section{Appendix 1: Methodology of study}

\begin{tabular}{|c|c|c|}
\hline Method & What will be involved & $\begin{array}{l}\text { What is expected to be } \\
\text { obtained by this method }\end{array}$ \\
\hline $\begin{array}{l}\text { Semi-structured in-depth } \\
\text { interviews }\end{array}$ & $\begin{array}{l}\text { M4V participants, } \\
\text { participants of general } \\
\text { mindfulness courses, GPs } \\
\text { and health workers, } \\
\text { academics and policy } \\
\text { makers. }\end{array}$ & $\begin{array}{l}\text { A qualitative } \\
\text { understanding of the } \\
\text { perspectives of various } \\
\text { mindfulness stakeholders } \\
\text { and course participants }\end{array}$ \\
\hline Focus groups & $\begin{array}{l}\text { 'Nudge' feasibility } \\
\text { discussions with M4V } \\
\text { participants, participants } \\
\text { of general mindfulness } \\
\text { courses, GPs and health } \\
\text { workers, academics and } \\
\text { policy makers. }\end{array}$ & $\begin{array}{l}\text { An insight into the views } \\
\text { of various stakeholder } \\
\text { and participant groups } \\
\text { feasibility of applying } \\
\text { and adapting indirect } \\
\text { interventions to } \\
\text { mindfulness promotion, } \\
\text { course, evaluative and } \\
\text { follow-up support } \\
\text { materials }\end{array}$ \\
\hline Observations & $\begin{array}{l}\text { Observations of health } \\
\text { promotion activities, } \\
\text { mindfulness courses, } \\
\text { council and Trust mental } \\
\text { health meetings }\end{array}$ & $\begin{array}{l}\text { Provide an insight into } \\
\text { dynamics of mindfulness } \\
\text { course settings, and } \\
\text { strategy and } \\
\text { implementation of mental }\end{array}$ \\
\hline
\end{tabular}


health and wellbeing policy in East Sussex

Document Review

Council Strategies,

Policies, Reports, Mindfulness course packs, evaluation forms and follow-up support materials
Provide a contextual understanding, inform the interviews and observations, provide analysis of the mindfulness agenda

\section{Appendix 2: Five ideas for creative interventions and questions for} interview:

\section{1) The adaption of current promotional materials using different language and framing.}

\section{2) Specifically for NHS staff groups:}

To increase awareness of mindfulness training and sustained positive lifestyle changes among GPs, therapists, Trust staff and others. SPFT has begun this process through MBCT trainers for staff, and physician buy-in has been identified by the Trust as a concern. 'Physician heal thyself' to counter iatrogenic processes:

- Pilot/adapt any current promotional materials that have been produced by SPFT for staff to encourage attendance on MBCT courses amongst staff

3) Follow-up peer support structures: how to encourage continued practice of mindfulness practices post-course.

Websites such as:

- http://www.stickk.com/about.php

- Online course such as: http://www.bemindfulonline.com/

- Online booster course 
- Online games like Superbetter: https://www.superbetter.com/

- Other social media networking strategies such as Facebook and Twitter.

- (Build a pilot website built if possible.)

- Mobile phone devices/iPhone apps to increase self-awareness and to cope with stress:

Motivating Change with Mobile: Seven Guidelines: Remind people of who they want to be, Foster an alliance (framing), Apply social influence, Show people what they could lose, Put the message where the action is, Reframe challenges

(http://www.scribd.com/doc/92691136/Motivating-Change-With-MobileSeven-Guidelines-2012). Margaret E. Morris (clinical psychologist and senior researcher at Intel) See Figures A, B, C, D. Images reproduced with kind permission of the author.

* Prompts for moods in the morning, evening and throughout the day, using an experience sampling program called MyExperience (see Figures E, F, G)

* Facebook App group: https://www.facebook.com/pages/MindfulnessApp-UK/354498511284908

* Youtube: The Mindfulness App http://www.youtube.com/watch?v=UN1mQ81ku-8\&feature=plcp

4) One-to-one and group setting mindfulness promotion adaptation (nudges used may differ between these settings): the language being employed and how are therapeutic options being presented/framed to explore acceptability to patients.

5) Improve evaluative forms and mechanisms to increase the improvement of future courses. 
Figure : A

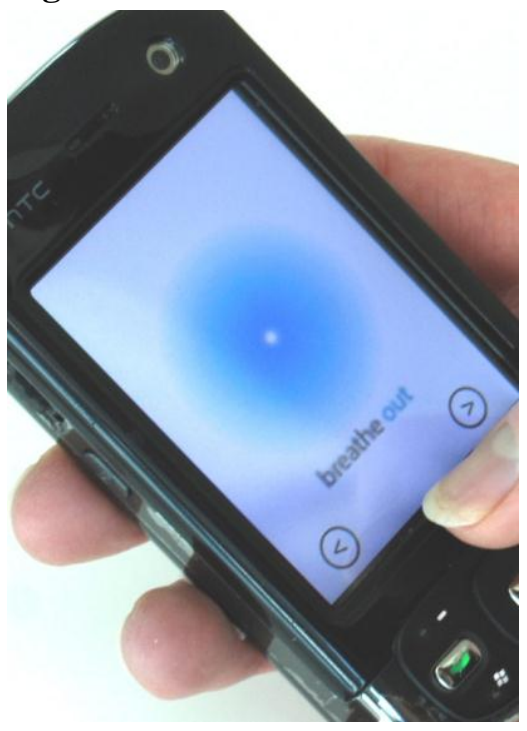

Figure : B




Figure : C

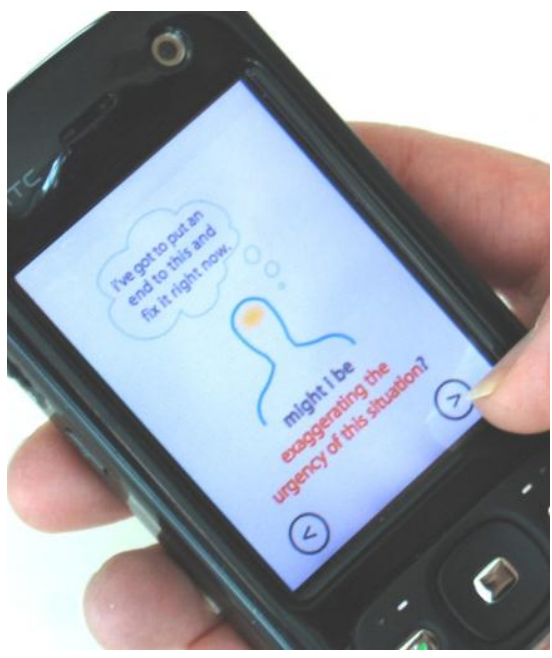

Figure : D

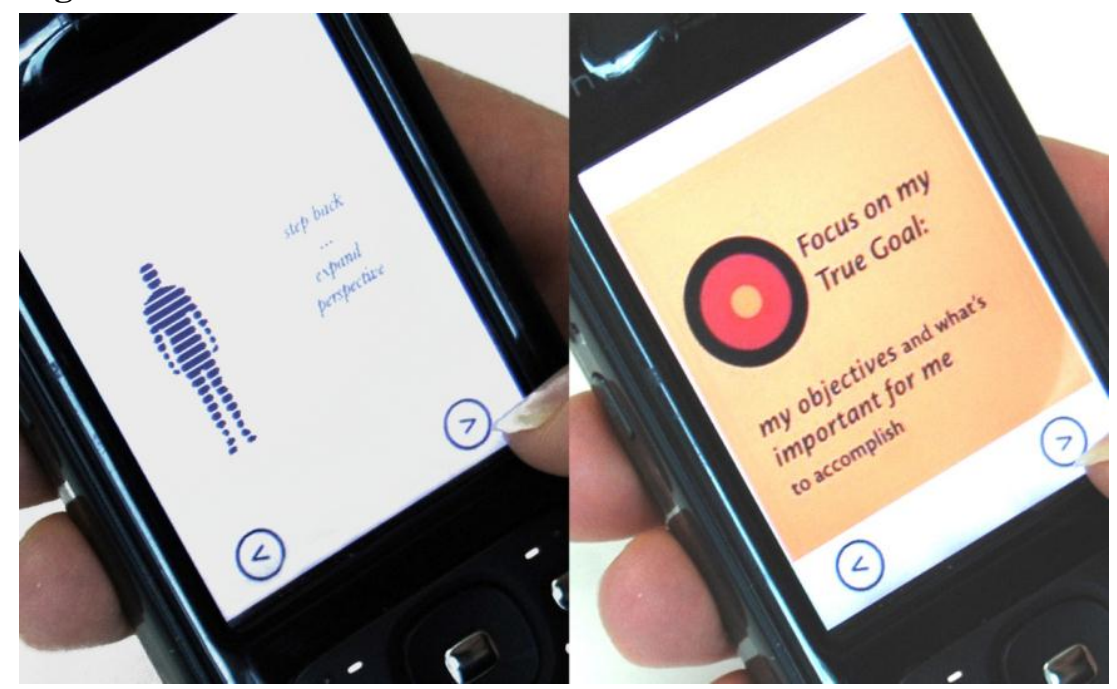


Figure : E

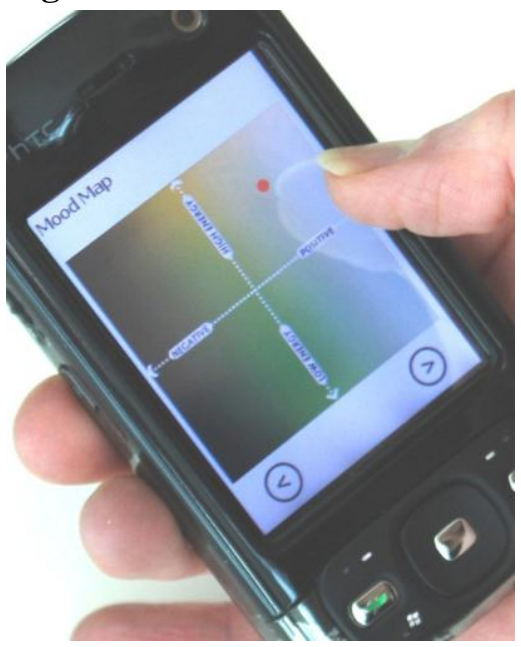

Figure : F






\section{Figure: G}

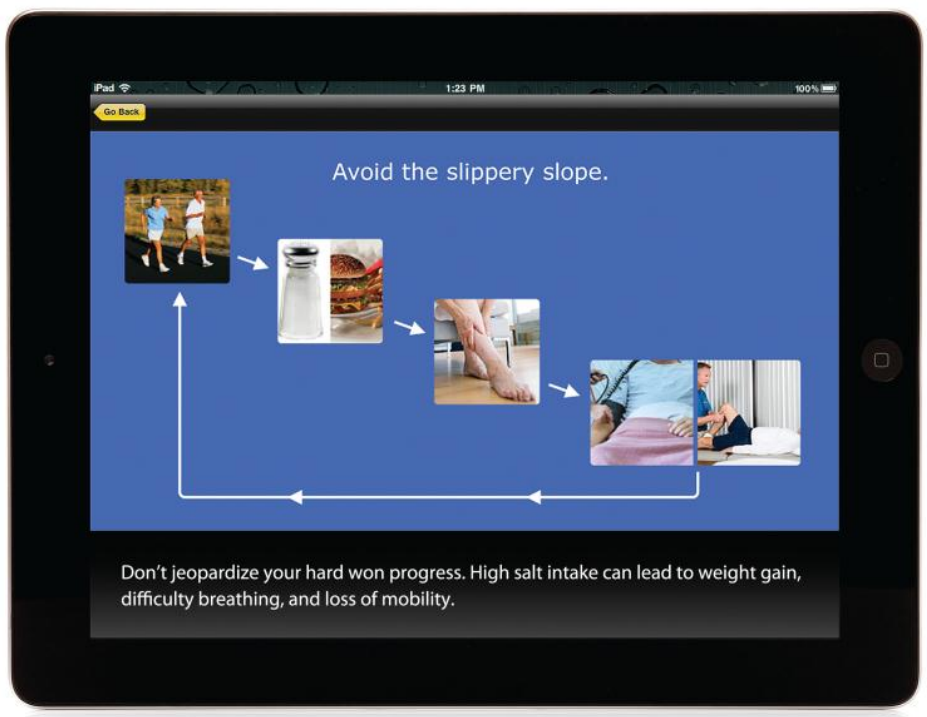

${ }^{1}$ Richard Thaler \& Cass Sunstein, Nudge-Improving Decisions about health, wealth and happines (London: Penguin Books Ltd, 2009), 5

2 Alan Gold and Lichtenberg, Don't call me "nudge": the ethical obligation to use effective interventions to promote public health. (The American journal of bioethics: AJOB,12 (2), 2012),18

${ }^{3}$ John Appleby, Chris Ham, Candice Imison \& Mark Jennings. Improving NHS productivity, More with the same not more of the same (Kings Fund Report, 2010) Viewed 18.6.12<www.kingsfund.org.uk/document.rm?id=8723Similar>

${ }^{4}$ Ruth Baer, Mindfulness training as a clinical intervention: A conceptual and empirical review (Clinical Psychology: Science and Practice, 10(2), 2003) , 125

${ }^{5}$ Sectco. Viewed 2.6.12< http://www.sectco.org/>

${ }^{6}$ Centre for Mindfulness Research and Practice, Bangor University: viewed 26.6.12<http://www.bangor.ac.uk/mindfulness/>

${ }^{7}$ Sussex Partnership NHS Foundation Trust.

viewed 15.6.12<http://www.sussexpartnership.nhs.uk/involved>

${ }^{8}$ Ibid 
${ }^{9}$ Rhys Jones, Jessica Pykett and Mark Whitehead. Governing temptation: Changing behaviour in an age of libertarian paternalism. Progress in Human Geography 35, 2011), 484

${ }^{10}$ Cabinet Office Institute for Government (2010), Viewed 18.6.12 $<\mathrm{http} / / / \mathrm{www}$.instituteforgovernment.org.uk/content/133/mindspace-influencingbehaviour-through-public-policy>

${ }^{11}$ Richard Thaler and Cass Sunstein (2009), 5

${ }^{12}$ Ibid

${ }^{13}$ Sally Shumaker, Judith Ockene, \& Kristin Riekert (ed). The Handbook of Behaviour Change, 3rd Edition (New York: Springer Publishing Company, 2009), 10

${ }^{14}$ Dan Ariely, Predictably Irrational-The Hidden Forces that Shape Our Decisions (London: Harper Collins, 2008)

${ }^{15}$ Alan Gold and Lichtenberg (2012), 18

${ }^{16}$ Dannahy, Mark Hayward, Clara Strauss, Turton, Harding, Paul Chadwick, Group person-based cognitive therapy for distressing voices: Pilot data from nine groups. J. Behav. Ther. \& Exp. Psychiat. 42, 2011) 114

${ }^{17}$ Department of Health, No health without mental health A cross-government mental health outcomes strategy for people of all ages

(2011)<http://www.dh.gov.uk/prod_consum_dh/groups/dh_digitalassets/document s/digitalasset/dh_124058.pdf>, 2

${ }^{18}$ Public Services Commission 2010, 5

${ }^{19}$ Rethink, Viewed 18.6.12<http://www.rethink.org>

${ }^{20}$ Gillian Bendelow Health, Emotion and the Body (Cambridge: Polity Press, 2009), 3

${ }^{21}$ Rethink: 18.6 .12

${ }^{22}$ AY Tien, Distributions of hallucinations in the population (Social Psychiatry and Psychiatric Epidemiology, 26), 291

${ }^{23}$ David Pilgrim \& Anne Rogers A Sociology of Mental Health and Illness 4th Ed, (Berkshire: Open University Press 1999), 72

${ }^{24}$ Ibid: 154

${ }^{25}$ Mike Jackson et al in Isabel Clarke Psychosis and Spirituality - Exploring the New Frontier (London: Wiley-Blackwell, 2010)

${ }^{26}$ Ibid

${ }^{27}$ Steven Hayes, Acceptance and Commitment Therapy, Relational Frame Theory, and the Third Wave of Behavior Therapy. Behavior Therapy, 35, 2004)

${ }^{28}$ Mike Jackson et al (2010), 487

${ }^{29}$ Ibid: 114

${ }^{30}$ Gillian Bendelow, (2010), 1

${ }^{31}$ Ibid: 2 
32 Ibid

33 Sarah Nettleton The Sociology of Health and Illness (Cambridge: Polity Press, 2010), 21

34 Ibid: 33

${ }^{35}$ Gillian Bendelow (2010), 2

${ }^{36}$ David De Vaus Research Design in Social Research (London: SAGE, 2001), 4

${ }^{37}$ Bill Fulford. Values-Based Practice: A New Partner to Evidence-Based Practice and A First for Psychiatry? (Mens Sana Monographs, Vol: 6, Issue: 1, 2008), 1

${ }^{38}$ Ruth Baer (2003), 125

39 Ibid

${ }^{40}$ Ibid: 139

${ }^{41}$ Sussex Partnership NHS Foundation Trust.

42 Ibid: 19

${ }^{43}$ Luke Bovens, The Ethics of Nudge in Grüne-Yanoff, Till and Hansson, Sven Ove, (eds.) Preference change: approaches from philosophy, economics and psychology. Springer, 2009), 209

44 Ibid: 210

${ }^{45}$ Peter Rainford and Jane Tinkler, Design Council Seminar Series - Innovating Through Public Services Seminar Series 2010-2011, Seminar 4: Designing for Nudge Effects: How behaviour management can ease public sector problems $\left(23^{\text {rd }}\right.$ February 2010) Viewed 23.4.12< http://eprints.1se.ac.uk/37812/1/Designing_digital_public_services_\%281sero\%29.p df>

${ }^{46}$ Mark Davies. The NHS reform debate must include patients. (Wednesday 4 May, 2011) Viewed 27.6.12

<http://www.guardian.co.uk/society/joepublic/2011/may/04/nhs-reform-debateinclude-patients-charities>

${ }^{47}$ NHS Clinical trials and Medical research. Viewed 16.3.12

<http://www.nhs.uk/conditions/clinical-trials/pages/introduction.aspx>

${ }^{48}$ Simon Lewin, Clare Glenton, Andrew Oxman, Use of qualitative methods alongside randomised controlled trials of complex healthcare interventions: methodological study. (BMJ; 339:b3496, 2009), 7 